\title{
Experimental Derivation of Thermal Parameters of the Stator-Winding Region in Thermal Analysis of PM Electrical Machines
}

\author{
Sabrina Ayat \\ Safran Tech \\ Châteaufort, France \\ sabrina.ayat@safrangroup.com
}

\author{
Haipeng Liu \\ University of Bristol, \\ Bristol, UK \\ liuhpbit@gmail.com
}

\author{
Fabien Chauvicourt \\ Université libre de Bruxelles, \\ Bruxelles, Belgium \\ fabien.chauvicourt@ulb.ac.be
}

\author{
Rafal Wrobel \\ Newcastle University \\ Newcastle upon Tyne, UK \\ rafal.wrobel@newcastle.ac.uk
}

\begin{abstract}
The majority of heat generated in a permanent magnet (PM) electrical machine is usually attributed to the stator-winding assembly. Here, the main dissipative heat flow from the winding body is typically through the stator core pack to the machine housing. A good understanding of the machine dominant heat transfer mechanisms is therefore crucial in thermal designanalysis. There are two main experimental techniques available in the literature to inform the stator-winding heat transfer, the shorttransient and steady-state DC thermal tests. Both tests allow deriving thermal parameters of the stator-winding region, including the winding-to-stator thermal resistance. The 'shorttransient' technique has been developed specifically for rapid thermal evaluation of complete machine assembly, e.g. inproduction machine quality assessment. In contrast, the 'steadystate' method is frequently time intensive, requiring for the tested hardware to reach thermal equilibrium. This drawback of the considerable testing time is particularly prominent for large machines with high thermal time constant. Both techniques can be applied to the complete machine as well as to a variety of the stator-winding sub-assemblies (motorette testing). Motorette testing enables a more controlled and repeatable testing environment with reduced time and resources required. This paper aims to connect both experimental techniques by comparing thermal parameters obtained from both complete stator and motorette thermal testing. The experimental work has been supplemented with theoretical analyses to identify applicability and limitations of both experimental methods.
\end{abstract}

Keywords-Model calibration, machine sub-assembly; thermal analysis; PM electrical machine, hardware testing.

\section{INTRODUCTION}

Accurate assessment of the conductive heat path from the stator-winding to the machine housing is crucial in thermal design-analysis of a wide range of electrical machines [1]-[12]. The derivation of parameters, such as thermal contact resistances and winding heat capacitances, typically requires some experimental work on a representative hardware. This is due to the variety of the build factors associated with the manufacture and assembly techniques used in construction of electrical machines. In particular, the stator-to-winding interface comprises an amalgam of slot liner, impregnation and air cavities, which depends on the winding arrangement, impregnation technique and material physical parameters, among others. The stator-to-winding interface is therefore notoriously difficult to predict theoretically. The common approach adopted in electric machine design for informing the stator-to-winding interface is to compare the winding thermal predictions with measured data from steady-state DC thermal tests on a machine hardware [12]-[17]. AC thermal tests might also be used, but require detailed analysis to separate various power loss components [13]-[18]. Both DC and AC thermal testing are frequently time and resources intensive, as the time required to reach thermal equilibrium can be significant. Also, a large number of test points might be required for all machine thermal parameters to be identified in a reliable manner.

Two main techniques are available in the literature to speed up the derivation of the stator-to-winding equivalent thermal resistance and winding heat capacitance [1]-[10]. The first method involves short-transient DC tests on machine hardware. The testing procedure consist of injecting known DC power loss into the machines winding until the stator core temperature rise reaches $1^{\circ} \mathrm{C}$. Such testing procedure emulates the stator core isothermal condition, which is the theoretical foundation of the 'short-transient' method [1]-[3]. Along with reduced testing time, the assumption of fixed stator core temperature results in the formulation of a well-defined mathematical model. The second method involves steady-state DC thermal testing of a machine assembly or alternative sub-assemblies like statorwinding sectors (motorettes). The motorette testing specifically allows for a more controlled testing environment, hence more reliable thermal data as compared with other hardware testing [4]-[10]. Further to these, the motorette testing assures reduced cost and time required for prototyping new hardware exemplars. Inherently, both short-transient and steady-state DC thermal testing techniques can be applied to analogous hardware. The techniques have nonetheless been developed for different applications. The use of the 'short-transient' method would be preferred for in-production quality assessment of complete machines, at the end of manufacturing process, whereas the motorette steady-state DC thermal testing is well suited to be used in the design process of new machine concepts.

This paper investigates the thermal data obtained from the 'short-transient' and 'steady-state' experimental methods, and identifies their applicability and limitations. A new 'steadystate' approach for the derivation of the winding heat capacitance is also presented. The thermal parameters for the stator-winding region have been derived by appropriately postprocessing the experimental data completed on stators and corresponding motorette assemblies. Furthermore, the practical use of complete stator and motorette hardware in thermal testing is elaborated on. 


\section{MACHINE ASSEMBLY AND HARDWARE EXEMPLARS}

A radial-flux interior PM machine has been selected for this investigation. The machine laminated rotor comprises a rareearth PM array with the individual PM blocks inserted into rotor cut-outs, Fig. 1. The machine laminated core pack has been manufactured using electrical steel (M270-35A, SiFe). The stator assembly includes a mush-wound double-layer concentrated winding formed using bundles of round Copper conductors $(\varnothing 0.8 \mathrm{~mm})$ with 44 strands per bundle. The conductors are coated with polyamide-imide enamel (Class $\mathrm{N}$ ). To ensure adequate electrical insulation, good mechanical rigidity and improved heat extraction from the winding body to the machine periphery, the complete stator-winding has been impregnated with varnish (Ultimeg 2000/U380). The complete impregnated stator-winding assembly is housed in a standard flange mounted aluminium frame (IEC 112M). Basic machine data is listed in Table I.

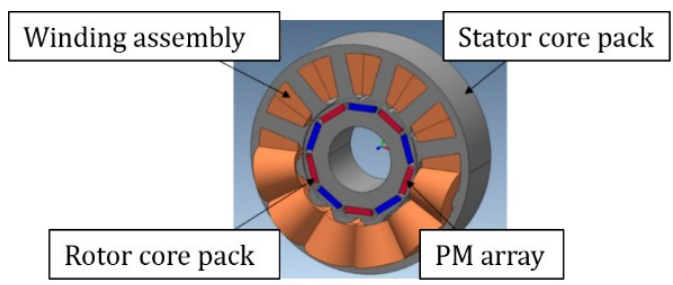

Fig. 1 Schematic drawing of the studied machine assembly with active regions indicated.

\begin{tabular}{ll}
\hline TABLE I: BASIC MACHINE DATA & \\
\hline Outer Diameter/ Active Length & $175 \mathrm{~mm} / 90 \mathrm{~mm}$ \\
Number of poles/slots & $10 / 12$ \\
Base rotational speed & $4200 \mathrm{rpm}$ \\
Rated power/torque & $12 \mathrm{~kW} / 30 \mathrm{~N} \cdot \mathrm{m}$ \\
\hline
\end{tabular}

Three motorettes, referred to as motorette-I, motorette-II, and motorette-III, have been built using identical materials and geometry as for the complete machine, apart from the core pack material. An individual motorette exemplar consists of a laminated stator core pack (NO20, SiFe), a mush-wound coil and slot liner (Nomex 410), Fig. 2a). The difference in core pack material for the stator and motorette assemblies is expected to have low impact on the winding-to-stator thermal resistance. To limit the influence of manufacturing variations, all analysed hardware exemplars have been built with a strict control of the assembly and manufacture processes, mimicking those of the final machine assembly. The exact location of each conductor within the slot is nonetheless unknown, and is expected to vary for each of the hardware exemplars. Hence, thermal tests on a batch of identical motorette assemblies allow accounting for the difference in conductor lay. In addition, thermal testing of the complete stator-winding assembly has been arranged to record data from individual coils. This provides more data to analyse effects associated with the manufacture repeatability. Fig. 2b) presents a photograph of the complete stator assembly, with the individual regions highlighted. Due to tooling restriction, the motorette core packs are $2 \mathrm{~cm}$ shorter than the complete stator active length. a)

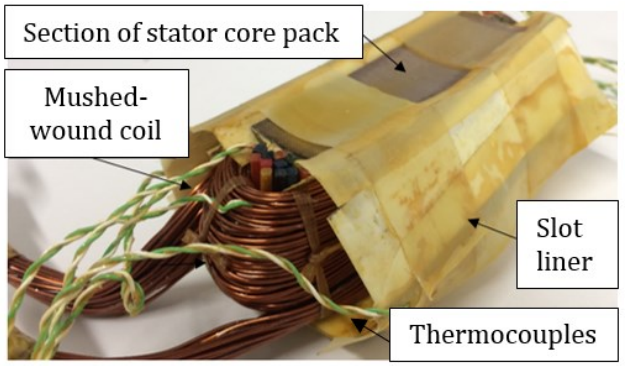

b)

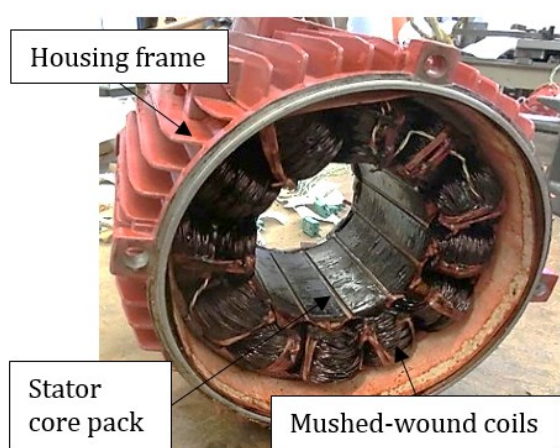

Fig. 2 Hardware exemplars, a) motorette assembly, b) stator assembly

A scaling factor has been applied when comparing motorette and complete stator data, allowing to correct for the differences in active length Ohmic resistance.

\section{EXPERIMENTATION}

A series of short-transient and steady-state thermal tests with DC excitation of the stator-winding assembly have been carried out. Thermal testing with DC excitation enables for a single, well-defined source of winding power loss.

Fig. 3a) presents the experimental setup for motorette tests. During the motorette testing, a hardware exemplar is mounted on an interfacing plate placed in an insulated chamber. Here, the heat generated within the winding body is conducted across the laminated core pack assembly through the interfacing plate to a temperature controlled liquid-cooled plate, referred to as 'cold plate'. This ensures a well-defined, unidirectional, heat path from the heat source to the heat sink. Such testing arrangement emulates the heat extraction via a liquid-cooled housing jacket. However, the approach is applicable for a wide variety of machine topologies and heat evacuation methods. To enhance heat transfer, a thermal paste has been applied between various interfaces of the experimental setup.

Fig. 3b) presents the instrumented stator assembly during a DC test. In this test, the stator phases are connected in series and excited with DC current. The housed stator assembly is placed in an environmental chamber with a controlled ambient temperature, and naturally cooled by convection. A plain cylinder and two end-caps formed using a thermally insulating material (Zotek N) have been placed inside the stator bore and on the stator ends. Such setup limits convective heat transfer from the stator periphery other than the housing frame. 
a)

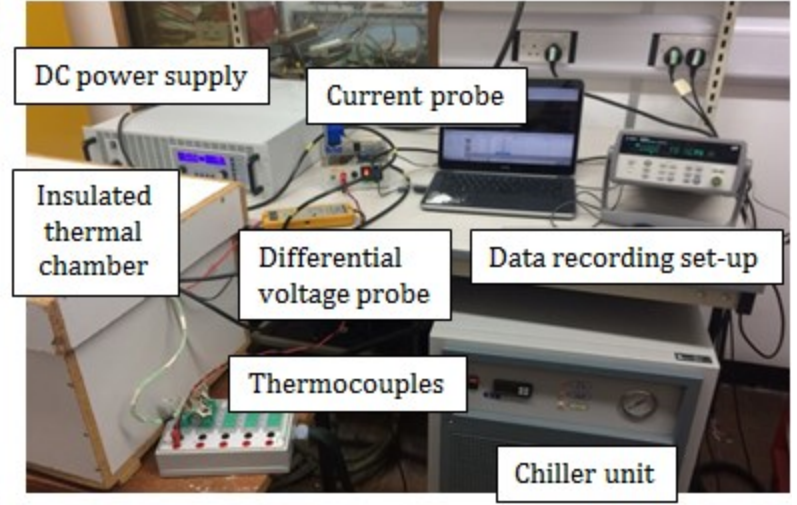

b)

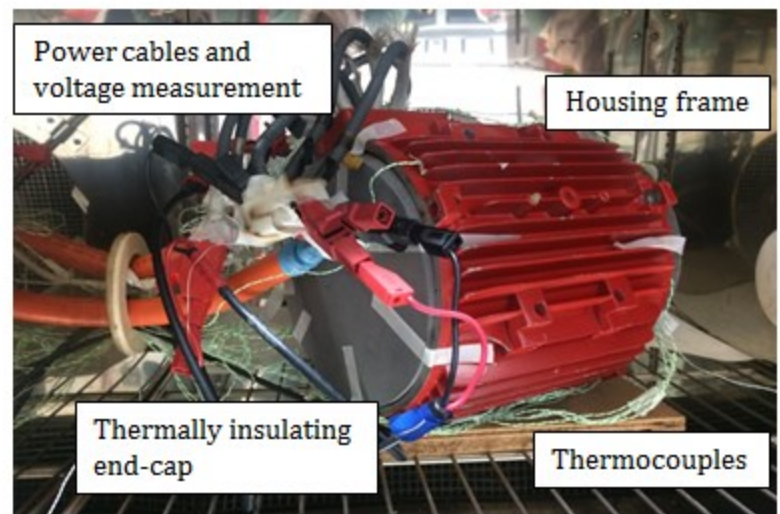

Fig. 3 Experimental setup, a) motorette DC test, b) stator DC test.

The test starts when the complete motorette assembly or stator assembly is at the reference cold plate temperature (requirement of the 'short-transient' method). The winding and core temperatures, current and voltage are logged at a sampling frequency of $4 \mathrm{~Hz}$ until the thermal equilibrium is reached (requirement of the 'steady-state' method). The thermal equilibrium is defined as a change of temperature lower than $1^{\circ} \mathrm{C}$ over 10 minutes. The measurements are repeated over a range of input excitation currents. The temperatures within various motorette and stator sub-regions are measured using type-K thermocouples. In addition, the averaged winding temperature has been monitored by measuring voltage and current.

$$
\frac{V(t)}{I_{d c}}=R_{\Omega, 0}\left(1+\alpha\left(T_{w}(t)-T_{0}\right)\right)
$$

where $R_{\Omega, 0}$ is the winding DC resistance at temperature $T_{0}$, $V(t)$ and $I_{d c}$ are the measured winding voltage and current, respectively. $T_{w}(t)$ is the averaged winding temperature and can be derived from (1), and $\alpha$ is the temperature coefficient of electrical resistivity of the conductor material used. Here, copper conductors have been used, $\alpha=3.93 \times 10^{-3} .{ }^{\circ} \mathrm{C}^{-1}$.

\section{MATHEMATICAL MODELS}

There is a large variety of modelling approaches adopted in thermal design of electrical machines, including the low-order thermal equivalent circuit (TEC) and high-fidelity finite element method (FEM).

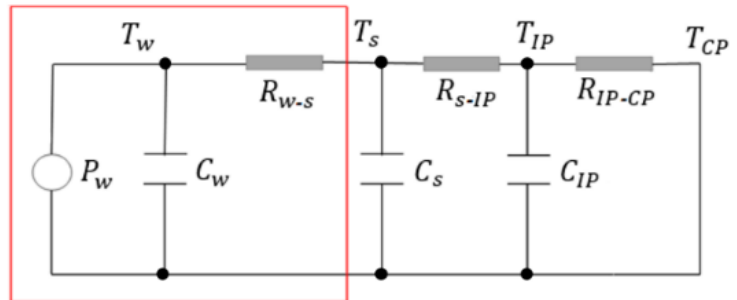

Fig. 4 Equivalent TEC of the motorette experiment apparatus. The circuit of interest is bordered by the red box, $R, P, T$ and $C$ are the thermal resistance, power loss, averaged temperature and heat capacity, respectively. The subscripts $w, s, I P$ and $C P$ correspond to the winding, stator core, interfacing plate and cold plate, respectively.

The TEC method is based on an equivalent lumped-parameter thermal network approach, where each sub-region of the machine assembly is represented by a temperature node. The 'short-transient' technique uses TEC modelling exclusively [1][3], while the 'steady-state' approach employs both FEM and TEC techniques [4]-[6]. Therefore, a TEC model has been adopted for this investigation. Fig. 4 presents the low-order TEC model of the motorette experimental apparatus, together with the nomenclature used. This paper investigates the efficacy of both methods for deriving the winding-to-stator thermal resistance $R_{w-s}$ and winding heat capacitance $C_{w}$. Consequently, only a portion of the circuit (bordered by the red box, Fig. 4) is considered. The winding DC power loss is expressed as follows:

$$
P_{w}(t)=V(t) I_{d c}
$$

where the time variation of both voltage and power loss is caused by the change of winding temperature. Applying the energy conservation law to the selected part of the circuit in Fig. 4 the following equation is obtained:

$$
P_{w}(t)=C_{w} \frac{d T_{w}}{d t}+\frac{T_{w}(t)-T_{S}(t)}{R_{w-s}}
$$

Here, $C_{w}$ and $R_{w-s}$ are assumed to be constant values, independent of temperature. Equation (3) is not limited to motorette testing, as the interfacing and cold plate temperatures are not part of the investigated circuit, and could be derived in a similar manner for stator and complete machine analysis. Several methods can be used to find the solution of a first order differential equation [19]. A discrete form of (3) is given as follows,

$$
P_{w, k}=C_{w} \frac{T_{w, k+1}-T_{w, k}}{t_{k+1}-t_{k}}+\frac{T_{w, k}-T_{s, k}}{R_{w-s}}
$$

which may be re-written as,

$$
T_{w, k+1}=T_{w, k}+\frac{1}{1+\frac{R_{w-s} C_{w}}{t_{k+1}-t_{k}}}\left(T_{s, k}+R_{w-s} P_{w, k}-T_{w, k}\right)
$$

Knowing that the power series of the exponential function,

$$
e^{x}=\sum_{0}^{\infty} \frac{x^{n}}{n !}
$$

and if,

$$
\left(t_{k+1}-t_{k}\right)=o\left(R_{w-s} C_{w}\right)
$$


Then,

$$
\frac{1}{1+\frac{R_{w-s} C_{w}}{t_{k+1}-t_{k}}} \cong \frac{t_{k+1}-t_{k}}{R_{w-s} C_{w}} \cong 1-e^{-\frac{t_{k+1}-t_{k}}{R_{w}-s C_{w}}}
$$

By combining (5) and (8), the expression presented in [1]-[3] is obtained:

$$
T_{w, k+1}=T_{w, k}+\left(T_{s, k}+R_{w-s} P_{w, k}-T_{w, k}\right)\left(1-e^{-\frac{t_{k+1}-t_{k}}{R_{w-s} C_{w}}}\right)
$$

The sampling frequency of the measured data must be high enough to ensure that (7) is true. Here, $4 \mathrm{~Hz}$ has been found to be sufficient for both motorette and stator tests.

\section{A. Short-Transient Approach}

The 'short-transient' approach is based on the assumption that the stator core pack is isothermal during short-transient DC tests, and thus only uses recorded data where the stator lamination temperature rise is within a $1^{\circ} \mathrm{C}$ margin. The DC test starts when the experimental apparatus is at thermal steadystate, i.e. all hardware sub-regions are approximately at reference temperature. Therefore, in a 'very short' time after starting the test, $T_{w}-T_{s}=\Delta T_{w-s} \approx 0$, and (3) becomes:

$$
P_{w}(t)=C_{w} \frac{d T_{w}}{d t}
$$

Combining (2) and (10),

$$
C_{w}=\frac{V(t) \cdot I_{d c} \cdot d t}{d T_{w}}=\frac{d W}{d T_{w}}
$$

Where $W$ represents the energy input into the winding. In practice, $C_{w}$ is derived from (11) by means of a linear regression for $W$ and $T_{w}$. Only a limited sample of the measured data is used for deriving $C_{w}$ to ensure that $\Delta T_{w-s} \approx 0$. Once $C_{w}$ is estimated, $R_{w-s}$ can be derived by curve-fitting (9) to the measured winding temperature. When deriving the thermal parameters, $T_{S}$ is replaced by a constant value $T_{0}$ in (9) due to the isothermal core assumption.

\section{B. Proposed steady-State Approach}

The 'steady-state' approach uses temperature and power loss measurements until thermal equilibrium. At thermal steady-state $\frac{d T_{w}}{d t}=0$ and (3) becomes:

$$
P_{w}=\frac{T_{w}-T_{S}}{R_{w-s}}
$$

Hence,

$$
R_{w-s}=\frac{T_{w}-T_{S}}{P_{w}}
$$

In [4]-[6], $R_{w-s}$ is found based on measured data from a series of thermal tests with various levels of DC excitation current. The approach proposed in this paper consists of estimating $C_{w}$ from curve-fitting (9) once $R_{w-s}$ has been estimated. Fig. 5 presents a schematic diagram summarizing the analysed methods, highlighting their underpinning fundamentals.

\section{'Short transient' method}

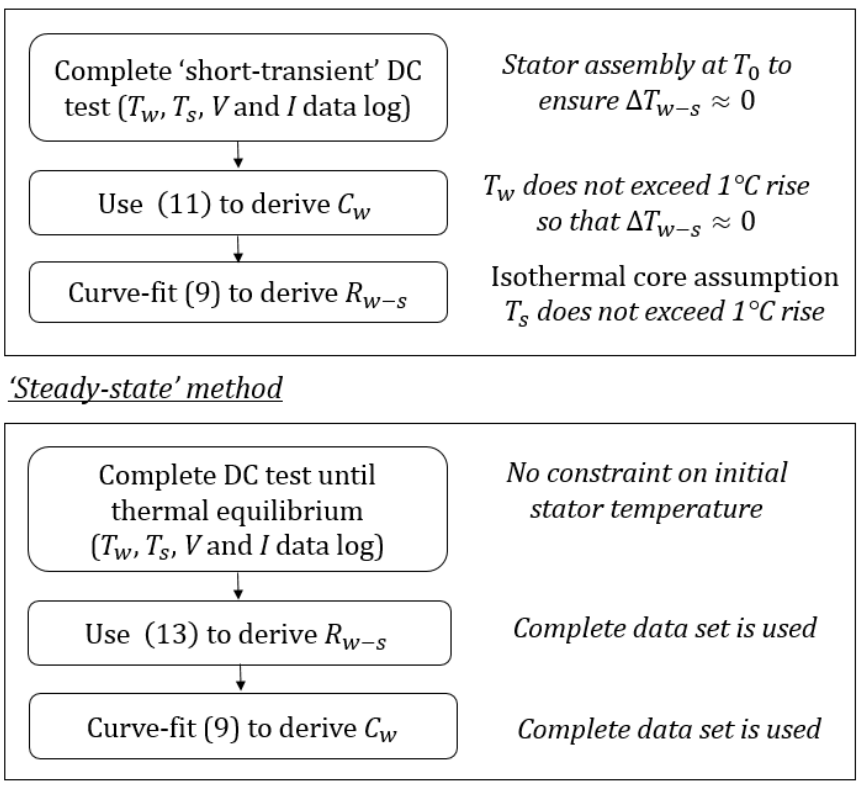

Fig. 5 Flow chart for deriving thermal parameters from the short-transient and proposed steady-state thermal tests

\section{MEASURED DATA}

\section{A. Winding Heat Capacitance}

Figs. 6a) and 6b) present measured and interpolated values of the winding thermal energy versus averaged winding temperature rise for both motorette (motorette-I) and complete stator-winding assemblies. The slope of the individual plots, $d W / d T_{w}$, represents here the winding equivalent thermal capacitance, $C_{w}$ given by (11). To ease the comparison, the power losses of the motorette have been scaled to the complete stator using the number of stator coils, Fig. 6a). The derived results from tests on complete stator-winding assembly show good agreement with the ones from motorette assemblies. No clear guidance is provided regarding testing procedure and data processing when deriving $C_{w}$, using the 'short-transient' method in [1]-[3]. However, it has been observed in [1]-[3] that the temperature data collected over a time window, where the winding temperature increase is no larger than $1^{\circ} \mathrm{C}$, have been used. An equivalent approach has been employed in this analysis. From tests on motorette-I, the measured $C_{w}$ correlates well, apart from the test point with excitation current $I_{d c}=60 \mathrm{~A}$. Considering the discrete expression of the winding thermal capacitance $C_{w}$ derived from (5),

$$
C_{w}=\frac{\left(P_{w, k}-\frac{T_{w, k}-T_{s, k}}{R_{w-S}}\right)\left(t_{k+1}-t_{k}\right)}{T_{w, k+1}-T_{w, k}}
$$

the error made by assuming that $\left(\Delta T_{w-s}\right)_{k} \approx 0$ will have more impact for lower $P_{w, k}$, i.e. lower excitation current, than for higher $P_{w, k}$. This explains the discrepancy observed in Fig. 6 between values at 'high' $\left(I_{d c} \geq 90 \mathrm{~A}\right)$ and 'low' $\left(I_{d c}=60 \mathrm{~A}\right)$ current excitations. Moreover, the measurement uncertainty for type-K thermocouples is equal to $\pm 1{ }^{\circ} \mathrm{C}$, which would have proportionally more impact on 'low' temperatures. 


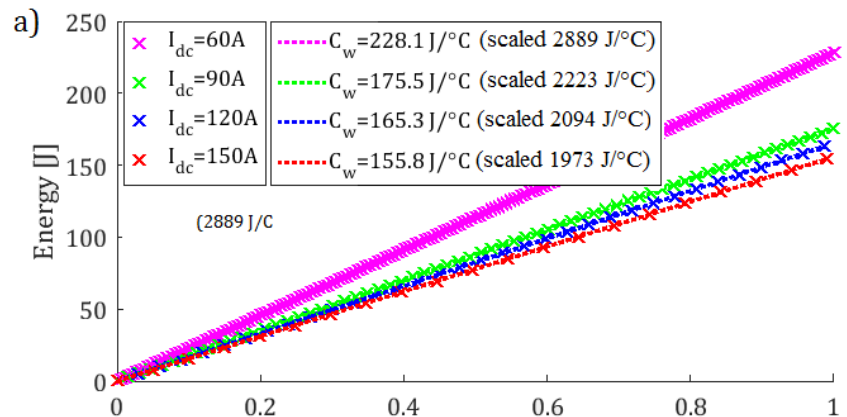

b)

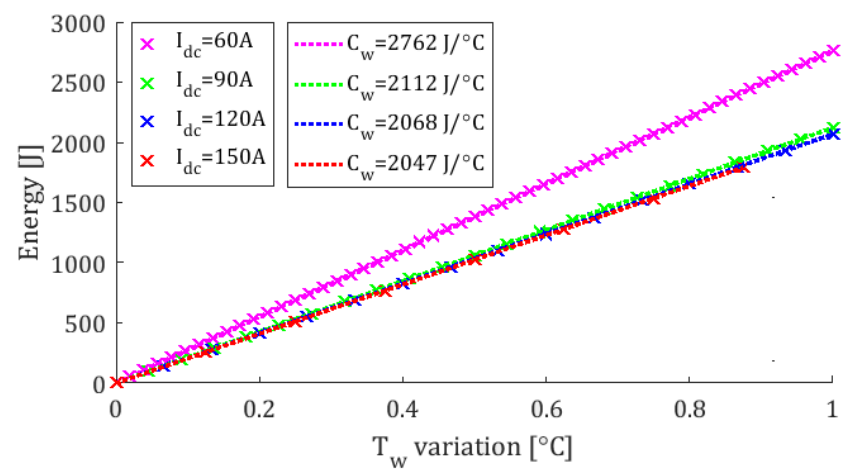

Fig. 6 Thermal energy vs. averaged winding temperature rise, a) motorette hardware (motorette-I), b) stator-winding assembly

If a different constraint had been chosen for $T_{w}$ (e.g. ' $T_{w}$ increase is no larger than $0.5^{\circ} \mathrm{C}$ ', or ' $T_{w}$ increase is no larger than $2^{\circ} \mathrm{C}^{\prime}$ ) then the obtained $C_{w}$ would have been dissimilar to the presented data. As for tests on motorette assemblies, the data obtained from tests on stator assemblies at 'low' current excitations $\left(I_{d c}=60 \mathrm{~A}\right)$ shows restricted applicability, highlighting the limits of the existing 'short-transient' method.

\section{B. Winding-to-Stator Thermal Resistance}

Fig. 7 presents the averaged $R_{w-s}$ obtained from (13) both for motorette and one phase of the complete stator-winding assembly, referred to as phase-A. To ease the comparison, the power losses of the motorette and stator phase have been scaled to the complete stator using the number of stator coils. The measured data correlates well when considering equivalent testing conditions for the analysed hardware, here less than $3 \%$ difference has been recorded. The results highlight the benefit of using motorette hardware as an alternative to stator assemblies for deriving the equivalent winding-to-stator thermal resistance in a rapid and repeatable manner for multiple design variants.

\section{RESULTS AND DISCUSSION}

The derived winding-to-stator thermal resistance $R_{w-s}$ and winding heat capacitance $C_{w}$ are compared in this section for both motorette-I and phase-A. To ensure a fair comparison, the same testing procedure has been used for alternative methods and hardware i.e. fixed sampling frequency for the temperature and power loss data, and time constraint set by $T_{s}$ to be no larger than $1^{\circ} \mathrm{C}$. Figs. $8 \mathrm{a}$ ) and $8 \mathrm{~b}$ ) present the estimated $R_{w-s}$ and $C_{w}$, respectively, for the investigated methods from stator and motorette test data.

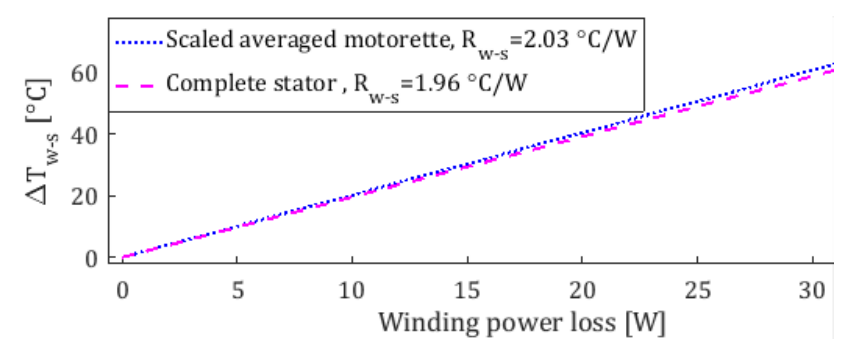

Fig. 7 Temperature difference between winding and back iron vs. winding DC power loss for scaled motorette data and stator assembly

The averaged winding-to-stator thermal resistance and winding heat capacitance values obtained earlier in the paper, have been used here as references when comparing the results. The $C_{w}$ value obtained at $I_{d c}=60$ is not included in the average.

From Fig. 8a), the existing 'short-transient' method fails to accurately predict $R_{w-s}$, demonstrated by the large variation in the estimated parameters at different current levels. A good correlation is observed between the motorette and stator data for the proposed 'steady-state' method. A slight decrease in $R_{w-s}$ predictions is observed for the latter, which may be explained by the thermal expansion of the winding and core pack assemblies at higher temperature, or by the fact that the thermal insulation of the set-up is not perfect, which may lead to increased heat dissipation at elevated temperatures.

From Fig. 8b), it can be observed that the estimated parameters from stator assembly measurements at a DC excitation current of $150 \mathrm{~A}$ show limited applicability for the 'steady-state' method. An explanation may be that at $I_{d c}=150$ A, it only takes a few seconds for $T_{s}$ to increase by $1^{\circ} \mathrm{C}$. This may not be sufficient to acquire a representative amount of data for curve-fitting. The parameter estimated from motorette analysis correlates well with the reference values, which validates the previous explanation: the motorette core pack is cooled by the cold plate, and therefore it takes a longer time for $T_{s}$ to increase by $1{ }^{\circ} \mathrm{C}$ at $I_{d c}=150 \mathrm{~A}$. It is important to note that if steady-state data had been used for the proposed method, the obtained value for $C_{w}$ would correlate well with the reference values.

The restricted applicability of 'low' excitation current, e.g. $I_{d c}=60 \mathrm{~A}$, for the 'short-transient' method has been previously justified by the limits of the assumption ' $\Delta T_{w-s} \approx 0$ '. Data from Fig. 8b) support this justification: for the proposed 'steadystate' method, the variation of $T_{S}$ is accounted for and the winding thermal capacitance is accurately predicted. The minimum testing time required to acquire a representative amount of data can be discussed according to the system time constant. The thermal time constant of the low-order TEC representation of the circuit of interest (bordered by the red box in Fig. 4) is:

$$
\tau=R_{w-s} C_{w}
$$

In practice, $\tau$ also depends on the thermal resistance and heat capacitance of the entire experimental set-up, e.g. housing frame for stator testing. 
a)

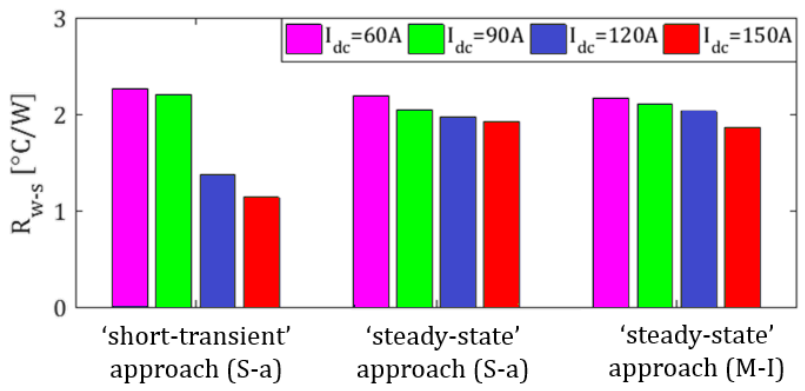

b)

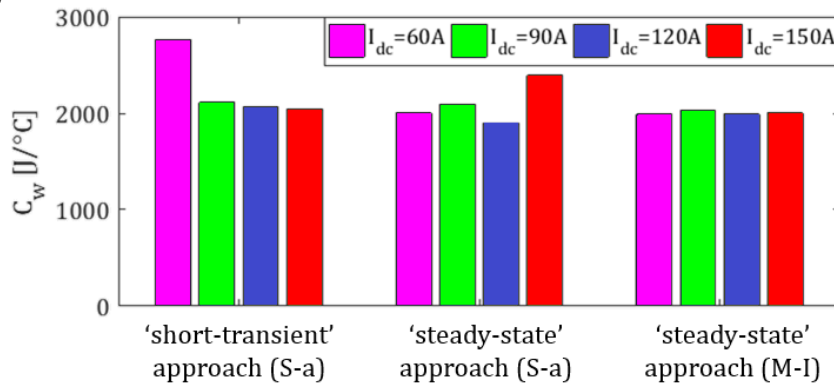

Fig. 8 Estimated parameters from motorette-I (M-I) and phase-A (S-a) for all investigated methods

\section{CONCLUSIONS}

A set of experimental techniques for deriving the equivalent winding-to-stator thermal resistance and winding heat capacitance has been evaluated in this paper. The 'shorttransient' approach has been developed for rapid testing, and has adequate use when analysing a known machine assembly, e.g. quality assessment for in-volume manufacture. However, when no information is available beforehand on the expected thermal parameters, a complete series of thermal tests should be done to gain confidence in the derived data. The assumption made in the 'short-transient' approach requires the core pack and winding assemblies to be at the same temperature when starting the experiment. This imposes the stator-winding assembly to return to the reference thermal equilibrium before starting a new test. Because of that, the total testing time might be only slightly shorter than a single steady-state test, but with significantly lesser data. The proposed 'steady-state' approach does not require the core pack and winding regions to be at the same temperature when starting the test. Therefore, a series of thermal tests can be completed without the need for the statorwinding assembly to return to the reference initial temperature. Moreover, the limited number of assumptions made for the core and winding temperatures makes the 'steady-state' approach the most reliable in this study.

The thermal tests on motorette assemblies have been shown to be a desirable alternative to experimentation on complete statorwinding hardware. In particular, the repeatability and welldefined testing conditions make it well-suited to inform design process of less conventional machine concepts, where the development time and cost is of consideration. The complete stator-winding testing is still an important part of the development process allowing the quality of the machine build to be assessed and helping to identify any issues, which might have serious consequences when performing dynamometric testing.

\section{ACKNOWLEDGMENT}

The authors would like to thank the European Union for their funding to this research (FP7 ITN Project 607361 ADEPT).

\section{REFERENCES}

[1] A. Boglietti, E. Carpaneto, et al., "Electrical Machine First Order ShortTime Thermal Transient Model: Measurements and Parameters Evaluation”, IEEE-IECON 14, Dallas, pp. 555-561, 2014.

[2] A. Boglietti; E. Carpaneto, et al., "Stator Winding Thermal Conductivity Evaluation: An Industrial Production Assessment”, IEEE Trans. on Industry Applications, Vol: 52, no: 5, pp. 3893-3900, 2016.

[3] A. Boglietti, M. Cossale, et al., "Thermal Conductivity Evaluation of Fractional-Slot Concentrated-Winding Machines", IEEE Trans. on Industry Applications, vol. 53, no. 3, pp.2059-2065, 2017.

[4] R. Wrobel, S. Williamson, et al., "Characterising the performance of selected electrical machine insulation systems" IEEE Energy Conversion Congress and Exposition, Montreal, pp.1-6, 2015.

[5] S. Ayat, R. Wrobel, et al., "Experimental Calibration in Thermal Analysis of Electrical Machines", IEEE Energy Conversion Congress and Exposition (ECCE 16), Milwaukee, September 2016.

[6] J. Godbehere, R. Wrobel, et al., "Experimentally Calibrated Thermal Stator Modelling of AC Machine for Duty Short Transient Operation", ICEM 2016.

[7] S. Ayat, R. Wrobel, et al., "Experiment Informed Methodology for Thermal Design of PM Machines", International Conference on Ecological Vehicles and Renewable Energies (EVER16), Monaco, 2016

[8] F .J. Marquez-Fernandez, J. H. J. Potgieter, et al., "Experimental validation of a thermal model for high speed switched reluctance machines for traction applications," International Conference on Electrical Machines (ICEM), Lausanne,Switzerland, 2016.

[9] R. Wrobel, S.J. Williamson, et al., "Impact of slot shape on loss and thermal behaviour of open-slot modular stator windings" Energy Conversion Congress and Exposition (ECCE), 2015 , pp. 4433-4440.

[10] J. Baker, R. Wrobel, et al., "A Methodology for Predicting the Thermal Behaviour of Modular-Wound Electrical Machines", IEEE Energy Conv. and Exposition (ECCE), pp. 5176-5183, 2014.

[11] A. Boglietti, A. Cavagnino, D. Staton, "Determination of critical parameters in electrical machine thermal models," IEEE Trans. Ind. Appl., vol. 44, no. 4, pp. 1150-1159, Jul./Aug. 2008.

[12] D. Staton, A. Boglietti, et al., "Solving the More Difficult Aspects of Electric Motor Thermal Analysis in Small and Medium Size Induction Motors," IEEE Transaction on Energy Conversion, vol. 20, no. 3, pp. $620-628$, September 2005.

[13] H. Liu, S. Ayat, R. Wrobel, C. Zhang, "Comparative Study of Thermal Properties of Electrical Windings Impregnated with Alternative Varnish Materials", in 9th IET International Conference on Power Electronics, Machines and Drives (PEMD), Liverpool, April 2018.

[14] W. Sixel, M. Liu, G. Nellis, B. Sarlioglu, "Cooling of Windings of Electric Machines via 3D Printed Heat Exchanger”, ECCE 18, Portland, September 2018, under press.

[15] S.Ayat, H. Liu, M. Kulan, R. Wrobel, "Estimation of Equivalent Thermal Conductivity for Electrical Windings with High Conductor Fill Factor", ECCE 18, Portland, September 2018, under press.

[16] G. Guemo, P. Chantrenne, et al., "Parameter identification of a lumped parameter thermal model for a permanent magnet synchronous machine", IEEE International Electric Machines \& Drives Conference (IEMDC 13), pp. 1316 - 1320, May 2013.

[17] F.Bosenuik, B. Ponick, "Parametrization of Transient Thermal Models for Permanent Magnet Synchronous Machine Exclusively Based on Measurements", IEEE SPEEDAM 14, pp. 295-301, 2014.

[18] B. Assaad, K. El kadri Benkara,et al., "Thermal design optimization of electric machines using a global sensitivity analysis", ICEM 16, Lausanne, pp. 1-5, 2016.

[19] M. Farkas, "Differential equations", North-Holland Publishing Co, Amsterdam, (1977). 